\title{
CORPO-PRÓPRIO: DE CORPO-OBJETO À CORPO-SUJEITO EM MERLEAU-PONTY
}

\section{BODY ITSELF: OF BODY-OBJECT TO THE BODY-SUBJECT IN MERLEAU-PONTY}

\author{
Klédson Tiago Alves de Souza* \\ José Francisco das Chagas Souza**
}

Recebido: 01/2017

Aprovado: 06/2017

\begin{abstract}
Resumo: Este artigo busca discutir os conceitos de Corpo-próprio e Corpo-Sujeito dentro do contexto filosófico de Maurice Merleau-Ponty. Desta forma, a discussão está voltada para se ver o homem como unidade em que não há separação entre o seu corpo (máquina) de sua razão. O objetivo é mostrar que em Merleau-Ponty o corpo-sujeito é este que está posto na realidade e que tem a capacidade de experienciar a si mesmo e o mundo. O mundo é isso que é, as coisas são o que aparecem ao homem, porém, ele tem a capacidade de experienciar e de ver sempre de uma perspectiva nova.

Palavras-chave: Merleau-Ponty. Corpo-Próprio. Corpo-Sujeito
\end{abstract}

\begin{abstract}
This article seeks to discuss the concepts of Body itself and Body-Subject within the philosophical context of Maurice Merleau-Ponty. In this way, the discussion is aimed at seeing man as a unit in which there is no separation between his body (machine) of his reason. The aim is to show that in Merleau-Ponty the subject body is the one who is put in reality and who has the capacity to experience himself and the world. The world is what it is, things are what appear to man, but he has the ability to experience and always see from a new perspective.
\end{abstract}

Key-works: Merleau-Ponty. Body itself. Body-Subject

O filósofo e psicólogo Maurice Merleau-Ponty nasceu em 14 de março de 1908, em Rocheford sur mer, na França. Em 1926 ingressou na École Normale Supérieure onde fez seus estudos de filosofia e onde conheceu Jean Paul Sartre e Simone de Beauvoir. Após formado em filosofia no ano de 1931 lecionou em vários liceus, logo depois regressou, em 1935, ao École Normale supérieure como tutor, em 1952 ganhou a cadeira de filosofia no Collège de France, ademais, de 1945 à 1952 fora coeditor da revista Les Temps Modernes junto à Sartre e em 04 de maio de 1961, aos 53 anos de idade em Paris na França morreu. $O$ pensador francês traz em suas discussões uma preocupação eminente com o que seja fenomenologia ${ }^{1}$ e isso é visível quando ver-se em seu prefácio à Fenomenologia da percepção: "O que é a fenomenologia? Pode parecer estranho que ainda se precise colocar essa questão meio século depois dos primeiros trabalhos de Husserl. Todavia, ela está longe de estar resolvida"

\footnotetext{
* Mestrando em Filosofia pela Universidade Federal da Paraíba (UFPB) Resolução no 19/2016 do Conselho Superior de Ensino, Pesquisa e Extensão (CONSEPE-UFPB). Graduado em Filosofia pela Universidade do Estado do Rio Grande do Norte UERN Membro do Núcleo de Estudo e Pesquisa em Filosofia Medieval: Pricipium.E-mail:magal.ic@hotmail.com

** Doutorando do PPGL/UERN. Possui graduação em Filosofia pela UECE, especialização em Metodologia do Ensino Superior e Mestrado em Filosofia - UFRN. Professor Adjunto II/UERN - Curso de Filosofia Campus Caicó. E-mail: dedasouza1@hotmail.com.

Problemata: R. Intern. Fil. V. 8. n. 2 (2017), p. 48-56 ISSN 2236-8612 doi:http://dx.doi.org/10.7443/problemata.v8i2.32509
} 
(Merleau-Ponty, 1999, p. 1).

Edmund Husserl (1859-1938) é um dos grandes influenciadores de Merleau-Ponty, este "fez um estudo cuidadoso de ideias II, quando ainda estava sob sua forma arquival não publicada, e sua influência pode ser percebida em Fenomenologia da percepção" (CERBONE, 2013, p. 150). É a partir das ideias de corpo e percepção em Husserl que Merleau-Ponty desenvolve sua filosofia. Cerbone (2013) ao falar sobre Husserl traz à tona a distinção entre corpo (Körper) e Corpo vivo (Leib) mostrando que corpo para a fenomenologia não é meramente o corpo material e sim o corpo que experiencia, que é experienciado e "o corpo-como-vivido". Destarte, Merleau-Ponty absorve bem esta filosofia Husserliana entendendo, como mostra Cerbone (2013, p. 151-152), que "o corpo não é experienciado como apenas mais um objeto material dentre outros, mas sim que é manifesto de um maneira categoricamente distinta".

A modernidade, dita iniciada com Descartes ${ }^{2}$ (1596 - 1650), tendeu a separar corpo e consciência. Nesta separação o corpo ganha um caráter meramente de objeto em que é visto como uma massa concreta repleta de partes que podem ser separadas, analisadas e compreendidas como objetos no mundo. Observa Lopes (in CAMINHA e SILVA, 2013, p. 123):

\begin{abstract}
Esta separação entre corpo e consciência não apenas permite conceber o corpo como objeto, mas também atribui à consciência a função de responsabilizar-se pela atividade mental de subsumir, por meio de conceitos, as informações obtidas por intermédio do corpo, como também construir as relações que acontecem no próprio corpo e entre este e o mundo. Enfim, esta concepção objetivista de corpo, que influenciou bastante a modernidade, traz atrelada à mesma uma concepção mentalista de consciência [...].
\end{abstract}

É perceptível que com a separação entre a consciência e o corpo quem ganha o poder de domínio é a razão, tendo em vista que o corpo é apenas um mero objeto em que transmite informações à razão pelos sentidos. Ademais, em Descartes parece haver um isolamento da res cogitans. O dualismo é fortemente apresentado na observação cartesiana do cogito, ergo sum (MARCONDES, 2005), tendo em vista que para Descartes isso - cogito, ergo sum - é o que se pode saber. Marcondes (2005, p. 169, grifo nosso) contextualiza o pensamento cartesiano descrevendo:

\footnotetext{
Sequer posso saber o que sou - um ser humano, dotado de um corpo etc. -, já que para isso precisaria ir além do puro pensamento, dependeria dos sentidos, de minha experiência, de conhecimentos adquiridos etc., o que não me é permitido pela certeza do cogito. Esta é a raiz do célebre dualismo corpo-mente em Descartes. Não podemos sequer afirmar a existência do corpo, porque, sendo este material, é de fato um objeto no mundo externo, sobre o qual não podemos ter certeza.
}

Assim se constitui o que em Descartes chama-se de solipsismo 
(MARCONDES, 2005), O isolamento total do eu em relação ao mundo exterior, e o que é mais interessante, ao próprio corpo. O que é o corpo então? No pensamento cartesiano, ao que parece, mero objeto da res cogitans. Porém, é contra esse dualismo e desmerecimento do corpo que adentra o pensamento de Merleau-Ponty.

Em 1945 Merleau-Ponty escreve a Phènomènologie de la Perception em que discute aspectos da filosofia e da psicologia referente à percepção. Dentro dos inúmeros temas que Merleau-Ponty trata nesta obra e seus vários conceitos quer-se aqui discutir a ideia de "corpo próprio" e a relação ou, se se pode dizer, a mudança de percepção de corpo-objeto para corpo-sujeito, isso para que esteja presente e bem esclarecida a ideia de corpo próprio que promove a ideia de um imbricamento entre a mente e o corpo.

Merleau-Ponty (1999, p. 133) levanta o seguinte problema:

Quando descrevia o corpo próprio, a psicologia clássica já Ihe atribuía "caracteres" incompatíveis com o estatuto de objeto. Ela dizia, em primeiro lugar, que meu corpo se distingue da mesa ou da lâmpada porque ele é percebido constantemente, enquanto posso me afastar daquelas. Portanto, ele é um objeto que não me deixa. Mas então ele ainda seria um objeto?

Como qualquer outro corpo na natureza somos submetidos às leis mecânicas naturais, já que somos corpóreos (CAMINHA, 2012). Deste ponto de vista poder-se-ia afirmar que somos corpo/objeto como qualquer outro. Ademais, Ponty (1999) levanta a questão relacionada ao corpo ser um objeto que não deixa esse sujeito que questiona-o e, por ser tão próximo "ele ainda seria um objeto?".

Faz-se necessário entender o que é corpo-próprio no pensamento merleaupontyano. No capítulo IV da Fenomenologia da Percepção (1999), Merleau-Ponty faz uma síntese sobre a ideia de corpo próprio elencando alguns pontos importantes. Na sua análise sobre a espacialidade corporal se conclui que: "Constatamos pela primeira vez, a propósito do corpo próprio, aquilo que é verdadeiro de todas as coisas percebidas: que a percepção do espaço e a percepção da coisa, a espacialidade da coisa e seu ser de coisa não constituem dois problemas distintos" (MERLEAU-PONTY, 1999, p. 205). O corpo é o que se tem de verdadeiro, ademais "Ser corpo [...] é estar atado a um certo mundo, e nosso corpo não está primeiramente no espaço: ele é no espaço".

Caminha (2012, p. 39, grifo nosso) discutindo a ideia de corpo próprio diz:

O ‘corpo próprio' é o corpo que experimento a mim mesmo, o outro e o mundo. É aquele que afirmo ser meu próprio corpo. Nesse sentido, nem todos os movimentos do corpo humano é regido por leis físicas. Mas como um corpo, que realiza movimentos mecânicos, provocados por causas externas, pode expressar movimentos intencionais e constitui-se sujeito por meio de tais movimentos? Se o 
nosso corpo é capaz de realizar movimentos que não dependem exclusivamente de uma causa externa, podemos afirmar que ele pode desempenhar movimentos voluntários, que se originam das intenções, dos desejos e das vontades do próprio corpo.

Até aqui se pode ser entendido que o corpo é um objeto por ser ele no espaço como assim o é uma cadeira, uma mesa e qualquer ser que seja corpóreo, porém, o corpo próprio ele se experiencia e experiencia a realidade que o circunda. O corpo próprio pode ele não ser sujeito (no sentido de se sujeitar, está disposto a alguma coisa ou ação) unicamente às leis da física mas, outrossim, às suas vontades e intenções, neste ponto distinguindo-se dos demais objetos corpóreos ${ }^{3}$, até porque o próprio Merleau-Ponty (1999) afirma não ser problema distinto a espacialidade e o ser da coisa quando fala de corpo próprio, ou seja, o ser não é distinto do estar no mundo, assim a coisa pensante (numa linguagem cartesiana) não tem um corpo no espaço, mas, a coisa pensante é um corpo no espaço (numa linguagem merleaupontyana). Dando embasamento a essa ideia de corpo próprio como algo que experimenta o mundo e mostrando a perspectiva de corpo próprio a partir da noção de perspectivismo afirma Lopes (in CAMINHA e SILVA, 2013, p. 125, destaque da autora e grifo nosso):

\begin{abstract}
A condição do corpo perceber por perspectiva advém da mesma condição na qual encontram-se submetidos corpo e mundo, condição denominada por Merleau-Ponty de 'ser no mundo'. Da mesma forma que os objetos estão no mundo, também o corpo encontra-se neste mesmo mundo submetido às suas condições. A posição espacial na qual o corpo está submetido é uma imposição indispensável e condição fundamental da experiência perceptiva. A condição de 'ser no mundo' faz com que o corpo possua uma determinação que lhe é anterior e transcendente. Essa condição direciona a forma como o corpo visa o mundo, o modo como o corpo é impulsionado para o que lhe é exterior.
\end{abstract}

O corpo está no mundo da mesma forma que as demais coisas, porém, ele percebe o mundo. Aqui está o grande diferencial do corpo, este percebe a realidade e percebe também a si mesmo. Afirma Merleau-Ponty já no prefácio à sua obra magna (1999, p. 3):

\footnotetext{
Eu não sou o resultado ou o entrecruzamento de múltiplas causalidades que determinam meu corpo ou meu "psiquismo", eu não posso pensar-me como uma parte do mundo, como o simples objeto da biologia, da psicologia e da sociologia, nem fechar sobre mim o universo da ciência. Tudo aquilo que sei do mundo, mesmo por ciência, eu o sei a partir de uma visão minha ou de uma experiência do mundo sem a qual os símbolos da ciência não poderiam dizer nada. Todo o universo da ciência é construído sobre o mundo vivido [...].
}

O eu, merleaupontyano, enquanto este ser corporal e também consciente 
não é resultado de múltiplas causalidade mas, é este ser que experiencia a realidade, ou seja, tem uma visão de mundo. Assim, confirma-se: não é o corpo mero objeto, mas é um corpo/sujeito, há um total imbricamente entre corpo e a consciência tornando o sujeito algo uno: corpo e mente. Assim o homem "pensa ao mesmo tempo que sua percepção penetra nas coisas e que se faz aquém de seu corpo" (MERLEAU-PONTY, 1971, p. 20).

Essa ideia de corpo sujeito é tão cara ao pensamento de Merleau-Ponty que parece ocorrer o que Lopes (2013) chama de inseparabilidade ontológica, ou seja, há uma perfeita união entre corpo e mente. Há momentos que a partir de ações sensíveis do próprio corpo humano há destaque para se pensar, a partir de Merleau-Ponty (1999, p. 137), como se dá o aparecimento da ideia de corpo sujeito, exemplo disso é o tocar de uma mão à outra:

\begin{abstract}
Quando pressiono minhas mãos uma contra a outra, não se trata então de duas sensações que eu sentiria em conjunto, como se percebem dois objetos justapostos, mas de uma organização ambígua em que as duas mãos podem alternar-se na função de 'tocante' e de 'tocada'.
\end{abstract}

Nisso o que se percebe é que o fato de uma mão tocar a outra não se dá a mesma sensação, parece que uma está exercendo uma função de sujeito enquanto a outra se está apenas solta no espaço. Lopes (in CAMINHA e SILVA, 2013, p. 126) falando da inseparabilidade ontológica que ocorre entre o corpo e a mente no pensamento de Merleau-Ponty mostra no próprio corpo humano como que membros desse mesmo corpo exercem ora função de objeto ora função de sujeito, havendo assim uma ambiguidade de sensações. Nesta ambiguidade está o sentido de se saber que acontecerá a mudança de sensação, ou seja, ora a mão que antes estava como objeto (sendo tocada) passa a ser sujeito da ação (tocar) ora a mão que era sujeito da ação passa a ser objeto. O problema dessa ação ambígua do tocar uma mão à outra é que "não podemos precisar, de maneira clara e distinta, qual é a mão toca e qual é a mão que é tocada" (CAMINHA, 2012, p. 40).

Com isso se afirma que não há uma consciência (mente) que seja sujeito de um corpo meramente objeto. Há um imbricamento total ou como Lopes (2013) chama uma inseparabilidade ontológica. É a unidade do corpo com a mente corpo/sujeito - que sente e pensa a ação, como se ver no comentário de Caminha (2012, p. 41):

É o próprio corpo que instaura processos subjetivos capazes de realizar movimentos voluntários. Para alcançar a compreensão do corpo sujeito é preciso adotar uma perspectiva de conceber o corpo humano que ultrapasse a explicação de seu funcionamento. 
Há ações ou algo que ultrapassa os limites do corpo, assim, corpo próprio é algo que vai além daquilo que é corpóreo. Ou seja, a unidade do corpo com a mente que deriva as vontades de ações e as ações da vontade.

A ideia de corpo próprio ganha mais proporções do que meramente o corpo (máquina) humano. Parece que há algo de afetivo, exemplo disso é quando falando do movimento Merleau-Ponty (1999, p. 138-139, grifo nosso) diz sobre o corpo:

\begin{abstract}
Movo os objetos exteriores com o auxílio de meu próprio corpo que os pega em um lugar para conduzi-los a um outro. Mas ele, eu o movo diretamente, não o encontro em um ponto do espaço objetivo para levá-lo a um outro, não preciso procurá-lo, ele ja está comigo - não preciso conduzi-lo em direção ao termo do movimento, ele o alcança desde o começo e é ele que se lança a este termo. As relações entre minha decisão e meu corpo no movimento são relações mágicas.
\end{abstract}

Merleau-Ponty chama essa relação afetiva - unidade entre consciência e corpo - de relações mágicas, isso porque o corpo não passa pelo mesmo processo do movimento que é estabelecido pelos outros objetos, ou seja, é preciso algo mover os objetos de modo que se estiver a sul venha a estar a norte, no corpo isso parece não ocorrer tendo em vista a relação imbricada que há entre a consciência e corpo, pois, "ele, eu o movo diretamente, não o encontro em um ponto do espaço objetivo para levá-lo a um outro, não preciso procurálo, ele já está comigo".

Corpo próprio e percepção são dois conceitos que devem andar juntos na filosofia de Merleau-Ponty, e parece que se entrelaçam tendo em vista que a percepção é a chave mestra da fenomenologia de Merleau-Ponty. Porém, para essa percepção haver ela deve "está relacionada a atitude corpórea" como alerta Nóbrega (2008) e, aqui se entende agora como o corpo humano (sensações). 0 corpo próprio em Merleau-Ponty abarca a ideia de corpo (sensações) mas não se limita a ele. Afirma Lopes (in CAMINHA e SILVA, 2013, p. 127):

\footnotetext{
Como o corpo próprio é o meio pelo qual o mundo existe para um sujeito, sua condição é ambígua porque ele, sob certo aspecto, não é tangível nem visível, já que ele é aquilo que vê e que toca os objetos. Ele se constitui num limite daquilo que é percebido. Enquanto campo de presença primordial, ele é uma zona de fronteira através da qual somos afetados e por meio do qual o mundo nos chega.
}

Se destaca então que o corpóreo (as sensações) estão presentes na ideia de corpo próprio pois é o que vê e o que toca, mas contudo, não se limita a isso porque "não é tangível nem visível".

É preciso deixar claro que a fenomenologia em Merleau-Ponty não despreza o corpo, muito pelo contrário, em O Visível e o Invisível (1971, p. 21) o filósofo realça a ideia de percepção atrelada como ação do corpo: "Antes da 
ciência do corpo - que implica a relação com outrem -, a experiência de minha carne como ganga de minha percepção ensinou-me que a percepção não nasce em qualquer lugar, mas emerge no recesso de um corpo". O corpo tem o seu espaço próprio na filosofia merleaupotyana, mas não complica toda a filosofia nele. Destarte, deve-se pensar o corpo como algo importante mas não o fim, pois, há a percepção que capta o mundo ao qual o corpo/sujeito está inserido e apreender ou percebe a realidade, o mundo vivido.

É sempre o movimento (corpo - razão) que está em cheque na filosofia fenomenológica de Merleau-Ponty, é um perceber percebendo, é um ver vendo, sentir sentindo. $\mathrm{O}$ corpo próprio é todo esse circundante que envolve a percepção. Em O Visível e o Invisível (1971, p. 15, grifo e destaque do autor) o autor consegue ipsis litteris mostrar o problema de toda a filosofia, afirma:

\begin{abstract}
Vemos as coisas mesmas, o mundo é aquilo que vemos - fórmulas dêsse gênero exprimem uma fé comum ao homem natural e ao filósofo desde que abre os olhos, remetem para uma camada profunda de 'opiniões' mudas, implícitas em nossa vida. Mas essa fé tem isto de estranho: se procurarmos articulá-la numa tese ou num enunciado, se perguntarmos o que é este nós, o que é este ver e o que é esta coisa ou este mundo, penetramos num labirinto de dificuldades e contradições.
\end{abstract}

É intrigante essa síntese que Merleau-Ponty faz, não basta lidar com o mundo como se percebe, parece que se é necessário dizer o que é este mundo que se percebe e dizer isto é o mesmo que entrar "num labirinto de dificuldades e contradições". Há não só um problema ontológico, mas linguístico o fato de não conseguir exprimir aquilo que o mundo é ou o que se é em si, mas sobre este problema da linguagem não é o foco da presente discussão.

O passo para se entender essa ideia de corpo próprio como sujeito é a abertura a realidade como destaca Merleau-Ponty (1999, p. 142)

\footnotetext{
Ser uma consciência, ou, antes, ser uma experiência, é comunicar interiormente com o mundo, com o corpo e com os outros, ser com eles em lugar de estar ao lado deles. Ocupar-se de psicologia é necessariamente encontrar, abaixo do pensamento objetivo que se move entre as coisas inteiramente prontas, uma primeira abertura às coisas sem a qual não haveria conhecimento objetivo.
}

O movimento da experiência é o que estar em cheque, é tudo aquilo que circunda o sujeito encarnado: a cultura, os afetos, o tempo, as relações sociais, etc., mas, vale salientar e reafirma que "Esse conceito de percepção só é possível porque Merleau-Ponty rompe com a noção de corpo-objeto, parte extrapartes e com as noções clássicas de sensação e órgãos dos sentidos como receptores passivos" (NÓBREGA, 2008, p. 142). O corpo-sujeito é este que está posto na realidade e que tem a capacidade de experienciar a si mesmo e o mundo. O mundo é isso que é, as coisas são o que aparecem ao homem, porém, 
ele tem a capacidade de experienciar e de ver sempre de uma perspectiva nova: "[...] é verdade que o mundo é o que vemos e que, contudo, precisamos aprender a vê-lo" (MERLEAU-PONTY, 1971, p. 16).

\section{Referências}

CAMINHA, Iraquitan Oliveira. Corpo, Motricidade e Subjetividade em MerleauPonty. In. Merleau-Ponty em João Pessoa. João Pessoa: Editora Universitária da UFPB, 2012, p. 39-47.

CERBONE, David R., Fenomenologia. Trad. Caesar Souza. 2ª ed., Petrópolis, RJ: Vozes, 2013.

LOPES, Rossana M., A concepção de corpo próprio em Merleau-Ponty. In. CAMINHA e ARAÚJO SILVA. Percepção, corpo e subjetividade. São Paulo, SP: LiberArs, 2013, p. 123-134.

MERLEAU-PONTY, Maurice O Visível e o Invisível. Trad. José Arthur Gianotti e Armando Mora d'Oliveira. São Paulo: Editôra Perspectiva, 1971.

Fenomenologia da Percepção. Trad. Carlos Alberto Ribeiro de Moura. 2ª ed., São Paulo: Martins Fontes, 1999.

NÓBREGA, Terezinha Petrucia. Corpo, percepção e conhecimento em MerleauPonty. In. Estudos de Psicologia. Vol. 13, No. 2, Natal, 2008, p. 141-148, disponível em: http://www.scielo.br/scielo.php?pid=S1413294X2008000200006\&script=sci arttext, Acesso em 26 de Outubro de 2015, às $14 \mathrm{~h}$.

\footnotetext{
1 Cf. CERBONE, 2013, p. 147: "uma característica proeminente da fenomenologia de MerleauPonty é a influência do movimento da Gestalt na psicologia. O movimento, cujas figuras dominantes incluem Max Wertheimer, Wolfgang Köhler e Kurt Koffka, rejeitou descrições 'sensacionalistas' da experiência perceptual - ou seja, teorias que concebem a percepção como envolvendo algum tipo de átomos sensórios ou senações como elementos fundamentais - em favor de uma teoria que enfatiza a prioridade das formas significativas inerentes à existência perceptual ('Gestalt' = configuração).

2 MARCONDES, 2005, p. 159: "A filosofia de Descartes inaugura de forma mais acabada o pensamento moderno propriamente dito, juntamente com a dos empiristas ingleses. [...] Entender as linhas mestras do pensamento de Descartes é, portanto, entender o sentido mesmo dessa modernidade, que ele tão bem caracteriza e da qual somos herdeiros até hoje, ainda que sob muitos aspectos vivamos precisamente a sua crise".
} 
3 BARBARAS (2003 APUD CAMINHA, 2012, P.39-40): "Os movimentos regidos pelas leis mecânicas são previsíveis. Se o nosso corpo estiver num plano inclinado e for empurrado com uma carga, de forma que ele não possa oferecer resistência, de forma previsível, ele se deslocará. Mas os movimentos voluntários são imprevisíveis, se consideramos o ponto de vista das leis da física. Logo, temos movimentos, determinados pelas leis mecânicas, e movimentos indeterminados, produzidos por um sujeito". 